\title{
Synthesis, Isolation, and Characterization of Isomeric Impurity of Dutasteride.
}

\author{
Dr. Saira Mulla ${ }^{1}$, Rajendra Nath Mukhopadhyay ${ }^{2}$, \\ Dr. Suhas Ramkrishana Kulkarni ${ }^{3}$, Dr. Sudesh Bhure ${ }^{4}$, Mr. Krishnan Iyer ${ }^{5}$. \\ ${ }^{I}$ Acharya Marathe College, Mumbai, India. \\ ${ }^{2}$ Department of Chemistry, JJIT University, JHUNJHUNU, RAJASTHAN -333001,India. \\ ${ }^{3}$ Examiner of Patents , patent office, Mumbai 37, India, \\ ${ }^{4}$ Cipla Ltd, Mumbai, India. \\ ${ }^{5}$ Sitec labs $(P v t)$ Ltd, Mumbai, India
}

\begin{abstract}
In the process development of dutasteride in the laboratory analysis showed some impurity peaks in HPLC ranging from 0.05 to $0.1 \%$. The same samples were analyzed by LCMS method and identified peak at $\mathrm{m} / \mathrm{z}$ 508 (desmethyl dutasteride), 530 (dihydro dutasteride) and 528 (isomer of dutasteride). Among these impurities a simple and rapid preparative high-performance liquid chromatography (HPLC) method has been developed to isolate and characterized 17alpha-N-[2,5-bis(trifluoromethyl) phenyl] carbamoyl-4-aza-5alpha-androst-1ene-3-one (alpha-isomer of dutasteride). Different isolation technique conducted and finally Isomeric impurity of dutasteride separated and Characterized by using Preparative HPLC,MS ${ }^{1} \mathrm{H}$ and ${ }^{13} \mathrm{C} N M R$ spectroscopy.
\end{abstract}

Keywords: Dutasteride, Impurities,Synthesis,Isolation,Characterization,flashchromatography, preparative hplc, mass spectra, nmr.

\section{Introduction}

Dutasteride was a dual inhibitor of $5 \alpha$-reductase, which was developed by Glaxo-Smith- Kline Company and approved by Food and Drug administration (FDA). For marketing in USA in June 2003. It was suitable to prevent and to treat benign prostatic hyperplasia ( BPH). Because dutasteride has lesser side effect and can effectively decrease prostatic volume, reduce the possibility of urinary retention, and hence prevent the risk related with operation and bio-process effect of BPH. The drug has been widely used in clinical treatment of benign prostatic hyperplasia ${ }^{(1,2)}$.

One of the usual and frequent male aged diseases was benign prostatic hyperplasia (BPH). According to statistic, the incidence of BPH among age males of elder than 50 was $30 \%--50 \%$, with age of 70-90 was $70 \%$. and males elder than 80 was even greater than $90 \%$. Therefore BPH was an important research topic for many scholars in china and abroad ${ }^{(3)}$.The therapy of BPH has been attracted wide attention in the medical society.

Steroid $5 \alpha$-reductase type 1 and type 2 are expressed tissue specifically in human ${ }^{(4)}$ and are responsible for local production of the more potent androgen dihydrotestosterone (DHT) from testosterone (t). DHT is believed to play an important role in the pathology of benign prostatic hyperplasia (BPH) ${ }^{(5)}$, acne ${ }^{(6)}$, hirsutism ${ }^{(7)}$, and male pattern baldness ${ }^{(8)}$.Dutasteride is currently available in the market as a drug for benign prostatic hyperplasia under the brand name of AVODART.

Dutasteride is a white to pale yellow power with the chemical name $(5 \alpha, 17 \beta)-\mathrm{N}-(2,5$ bis(trifluoromethyl) phenyl)-3-oxo-4-azaandrost-1-ene-17-carboxamide. It's CAS No is 164656-23-9.The Chemical formula is $\mathrm{C}_{27} \mathrm{H}_{30} \mathrm{~F}_{6} \mathrm{~N}_{2} \mathrm{O}_{2}$ and the molecular weight of Dutasteride is $528.53 \mathrm{gm} / \mathrm{mol}$. The molecular structure of Dutesteride is as below:

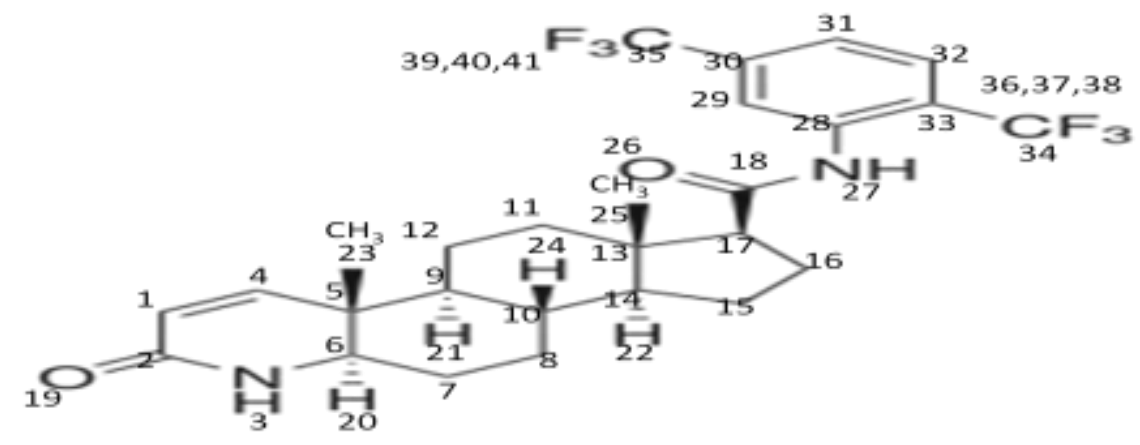


Physicochemical properties: Dutasteride is a white to pale yellow powder with a melting point of 242 to $250^{\circ} \mathrm{C}$. It is soluble in ethanol $(44 \mathrm{mg} / \mathrm{mL})$, methanol $(64 \mathrm{mg} / \mathrm{mL})$ and Polyethylene glycol $400(3 \mathrm{mg} / \mathrm{mL})$, but it is insoluble in water.

There are several process impurities/related substances associated with the manufacture of Dutasteride. Different process related impurities have been observed with various synthetic route and/ or manufacturing process. Three known impurities have been mentioned in international pharmacopoeia. All these impurities are never present together while we are preparing bulk drug or formulation.

The international pharmacopoeia specifies that individual impurity is not more than $0.1 \%$ and total impurity is not more than $0.7 \%$. During the process development of dutasteride in the laboratory analysis showed some impurity peaks in HPLC ranging from 0.05 to $0.1 \%$. A comprehensive study has been carried out to isolate or to prepare and characterization of this impurity. To the best of our knowledge of regulatory authorities ${ }^{(9)}$ all the impurity which are at the level of $>0.1 \%$ must be identified and characterized.

A literature search revealed that only analytical procedure is available but nobody has reported synthesis, isolation, and characterization of impurity in the purified starting from 3-oxo-4-aza- 5 $\alpha$ - androstane$17 \beta$ carboxylic acid ${ }^{(10)}$. The present communication involves the isolation or preparation of impurity and characterization by chromatographic and spectroscopic technique.

\section{Experimental Section}

\subsection{Materials and reagents :}

The raw material of Dutasteride was received from Sitec labs Mumbai, India. The HPLC grade acetonitrile and methanol solvents were obtained from Merck co, Mumbai,India. The preparative grade ethyl acetate and hexane were obtained from Merck co, Mumbai, India.

\subsection{High performance liquid chromatography (HPLC):}

An Agilent HPLC system equipped with 1100 series low pressure quaternary gradient pump along with pulse dampener, Photo diode array detector with auto liquid sampler handling system has been used for the analysis of the sample. An Inertsil C-18, $4.6 \mathrm{~mm} \times 25 \mathrm{~cm} \times 5 \mu$ column was employed for the separation of Isomer of Dutasteride. The column eluent was monitored at detection wavelength $215 \mathrm{~nm}$. The isocratic gradient pattern employed for the separation of isomeric impurity of Dutasteride was as ACN: Water $=55$ : 45. Chromatography was performed at room temperature using a flow rate of $1.0 \mathrm{ml} \mathrm{min}^{-1}$. Data was recorded by using Chem station software.

\subsection{High performance liquid chromatography (Preparative HPLC):}

Preparative HPLC is the technique of choice for compound isolation and purification within the pharmaceutical and life science industries. Agilent technologies purification solution from nano gram to gram sample quantities. Agilent 1200 Series purification system with low delay volumes optimized for high recovery and purity, with PDA detector and flow rate is 0.001 to $100 \mathrm{ml} / \mathrm{min}$ with max. Pressure 400 bar. A Zodiac $250 \mathrm{~mm} \times 20 \mathrm{~mm} \times 10 \mu$ silica column was employed for the separation of isomeric impurities of Dutasteride. Solvent used for the separation was Hexane: Ethyl acetate $=15: 85$, with flow rate of $10 \mathrm{ml} / \mathrm{min}$, with the detection of $254 \mathrm{~nm}$.

\subsection{Flash Chromatography:}

Flash chromatography known as medium pressure chromatography, was differed from the conventional technique. The compound of interest should have a TLC Rf of $=0.15$ to 0.20 in the solvent system I choose. Binary solvent system with one solvent having a higher polarity of the eluent. Higher polarity of solvent increases rate of elution for all compounds. Common binary solvent systems in order of increased polarity are dichlomethane/hexane, ether/hexane, hexane/ethyl acetate and dichloromethane/methanol. For the separation of dutasteride isomeric impurity used Teledyne ISCO combi-flash, solvent used Hexane/ Ethyl acetate and column used $24 \mathrm{gm}$ silica of $40 \mu$ size. Detection wavelength was $254 \mathrm{~nm}$ with the flow of $10 \mathrm{ml} / \mathrm{min}$.

\subsection{Mass Spectrometry (LC-MS/MS):}

The LC-mass spectrometry (MS) and MS-MS studies were carried out on an Ion trap 6320

Series electron spray ion trap spectrometer (Agilent Technologies). The source voltage was kept at $3.0 \mathrm{kV}$. Parameters: nebulizer gas $=30 \mathrm{psi}$; dry gas $=3 \mathrm{~L} / \mathrm{min}$; dry temperature $=150{ }^{\circ} \mathrm{C}$; capillary voltage $=24500$ to $21500 \mathrm{~V}$. Nitrogen was used as both a sheath and auxiliary gas. Mass range was kept at $\mathrm{m} / \mathrm{z}$. 50-600.The chromatography conditions and mobile phase are as described under the heading "HPLC" earlier. The flow rate was maintained at $1 \mathrm{~mL} / \mathrm{min}$. 


\subsection{Nuclear Magnetic Resonance:}

The $1 \mathrm{H}$, and $13 \mathrm{C}$ nuclear magnetic resonance(NMR) spectroscopy experiment of the impurity was carried out at a frequency of $500 \mathrm{MHz}$ at $25^{\circ} \mathrm{C}$ on an NMR spectrometer (Varian, Palo Alto, California). $1 \mathrm{H}$ and $13 \mathrm{C}$ chemical shifts are reported on the $\delta$ scale in ppm relative to tetra methyl silane 0.00 and $\mathrm{CDCl}_{3}(\delta 77.00$

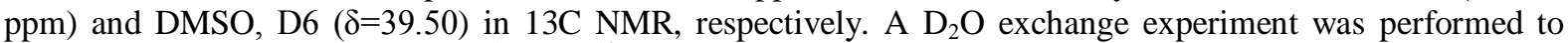
confirm the exchangeable protons. ${ }^{1} \mathrm{H}$ and ${ }^{13} \mathrm{C}$ experiments were run using a mixing time of $1000 \mathrm{~ns}$.

\subsection{FT-IR spectroscopy:}

The IR spectra were recorded in the solid state as $\mathrm{KBr}$ dispersion medium using Perkin Elmer spectrum 100 FT-IR spectrophotometer.

\section{Synthesis of Impurity}

Synthesis of $17 \infty-\mathrm{N}[2,5$ bis( trifluoro methyl) phenyl] carbamoyl-4- aza- 50-androst- 1- ene- 3-one ( $\infty$-isomer of dutasteride).

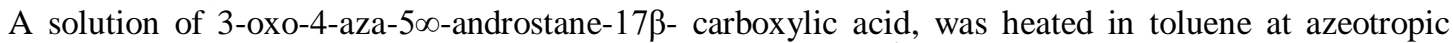
reflux for $40 \mathrm{~min}$. To the resulting solution was cooled to 25 to $30^{\circ} \mathrm{c}$, pyridine was added under nitrogen atmosphere, followed by thionylchloride for $30 \mathrm{~min}$. The reaction mass was stirred for $2.5 \mathrm{hrs}$ at $30^{\circ} \mathrm{c}$ Ammonia gas was passed into the reaction mass for 6 hrs. The obtained solid was filtered and dried.

The above obtained solid taken in xylene, added with potassium carbonate and heated for $2 \mathrm{hrs}$, then cooled to $30^{\circ} \mathrm{c}$. Copper powder and [2, 5 bis(trifluoromethyl) iodo benzene were added and the resulting mixture was heated to $140^{\circ} \mathrm{c}$ with vigorous stirring for the period of 55hrs. After cooling the reaction mass to $55^{\circ} \mathrm{c}$, filtered out the copper powder and the organic layer was distilled out under vacuum and the solid obtained was the mixture of $\infty$ and $\beta$ isomer of dutasteride. This solid was taken for preparative isolation for purification of $\infty$ - isomer of dutasteride for characterization.

\subsection{Detection of impurity by HPLC :}

\section{Results and Discussion}

Typical analytical HPLC chromatogram of dutasteride bulk drug and it's isomer obtained by using the HPLC method discussed under the heading "High performance Liquide Chromatography (analytical)" is shown in figure 1 . The targeted impurity under study are marked as $\infty$-isomer impurity eluted at retention time of about $27.683 \mathrm{mins}$ and the dutasteride eluted at retention time of about 30.033 mins. respectively.

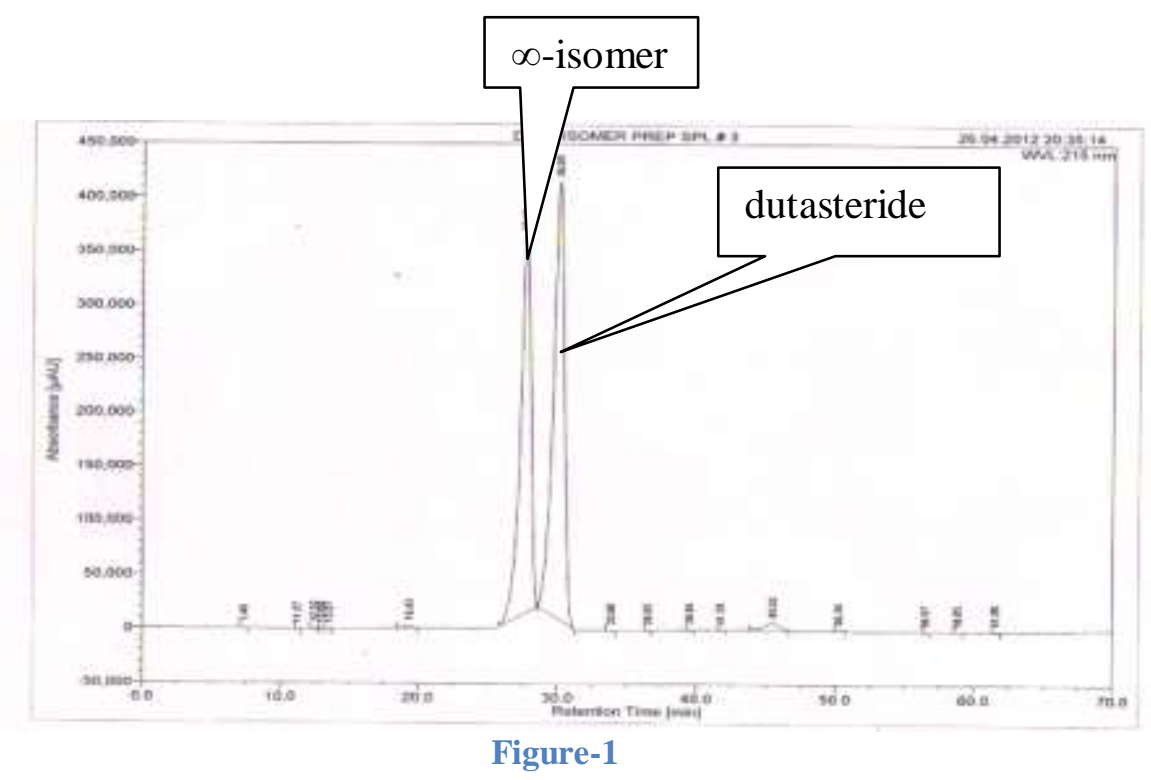

\subsection{Isolation of the impurity by Flash Chromatography:}

A simple normal phase chromatographic system, discussed under the heading "Flash Chromatography" was used for increasing the percentage of the impurity, it does not give the pure material for characterization.

\subsection{Isolation of the impurity by prep-HPLC:}

A simple normal phase chromatographic system, discussed under the heading, "High performance Liquid Chromatography (preparative) was used for isolation of the impurity. In this chromatographic system, dutasteride eluted at about 21.623 mins whereas the isomer impurity eluted at about 17.597 mins 
respectively.The isomer impurity fraction was collected between $17.592 \mathrm{~min}$ to $20.0 \mathrm{~min}$ (Figure-2). The impurity fraction was concentrated at room temperature under high vacuume on a Buchii Rotavapour Model R124. The concentrated volume take in acetonitrile solvent and put it in the Lyopholizer for getting solid isomer impurity. Purity of the impurity was tested in analytical method discussed under the heading, "High Performance Liquid Chromatography"(HPLC). The purity was found to be $99.119 \%$ before carrying out spectroscopic experiments.

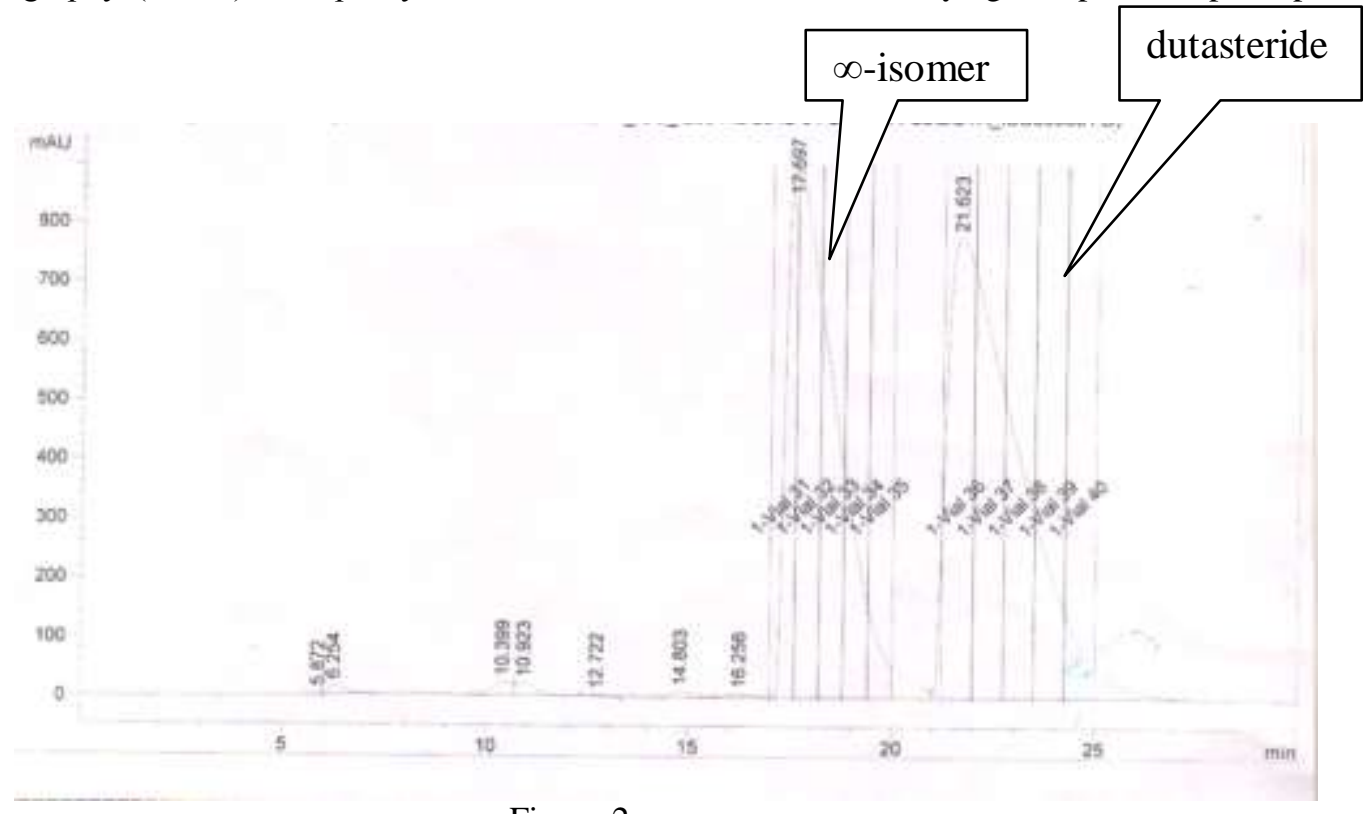

Figure-2

The isolated impurity was obtained $99.119 \%$ pure and showed in the figure-3. The purity was obtained by the method discussed under the heading," High performance liquid chromatography (HPLC)".

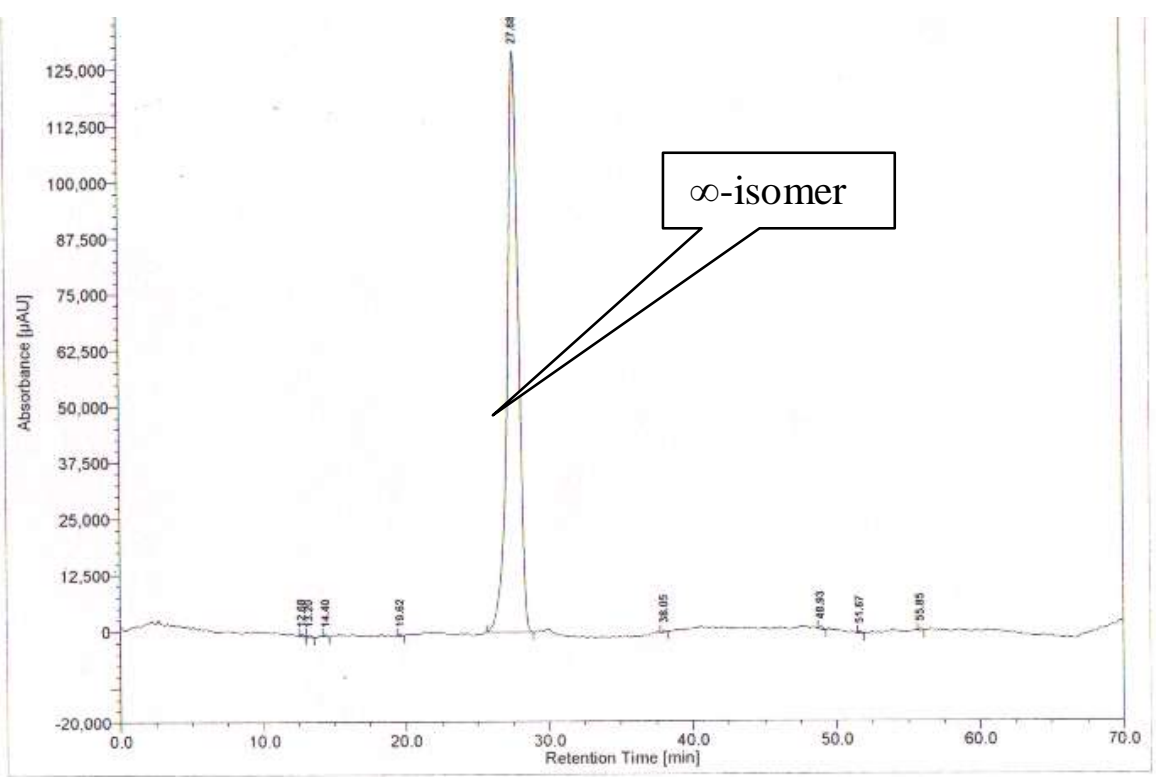

Figure-3

\subsection{LC-MS/MS analysis:}

LC-MS/MS analysis of dutasteride bulk drug sample and isomer impurity of dutasteride was performed using the chromatographic system as described under the heading "Mass Spectrometry (LC-MS/MS)". Result of LC-MS/MS analysis revealed that impurity (isomer of dutasteride) exhibited molecular ion at $\mathrm{m} / \mathrm{z}(\mathrm{M}+1)=529.4$ and $(\mathrm{M}-1)=527.1 \mathrm{amu}$. (Figure-4) and dutasteride API exhibited molecular ion at $\mathrm{m} / \mathrm{z}(\mathrm{M}+1)=529.4 \mathrm{amu}$, and (M$1)=527.1$ (Figure-5).Figure-5 exhibited the molecular masses of dutasteride API and its impurity. Based on this fact it was assumed that the impurity was similar to that of dutasteride which might be a isomer. 


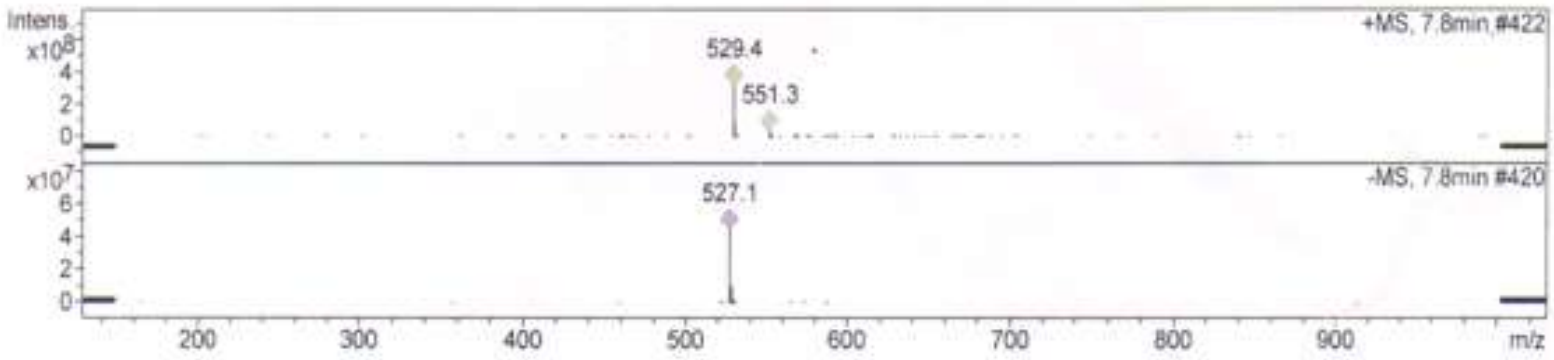

Figure-4

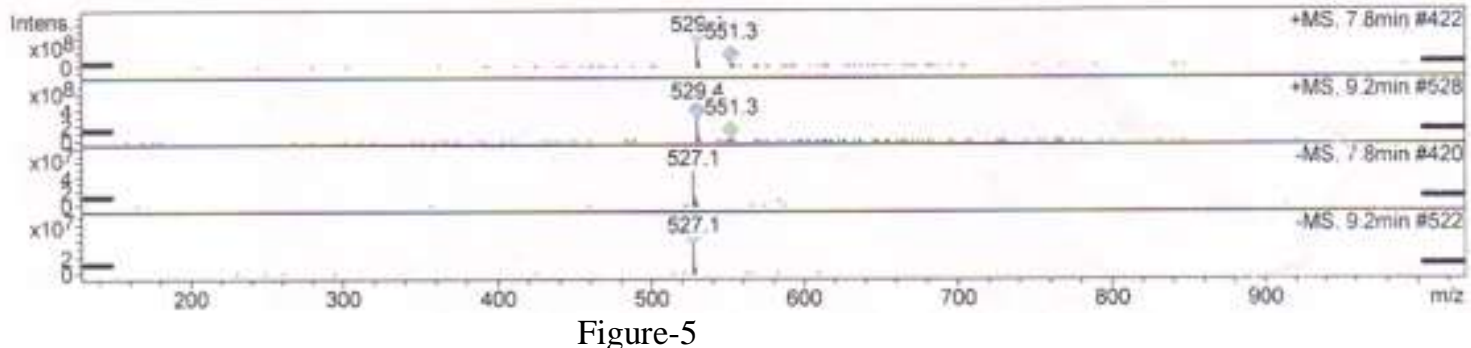

\section{Structure Elucidation}

(comparision study of dutasteride and isomer impurity)

The IR spctra recorded in the solid state as $\mathrm{KBr}$ dispersion.IR spectrum at $1683 \& 1607 \mathrm{~cm}^{-1}$ clearly indicate the presence of two carbonyl groups. IR spectrum of dutasteride and impurity exhibited in Figure- 6 and Figure-7 respectively.

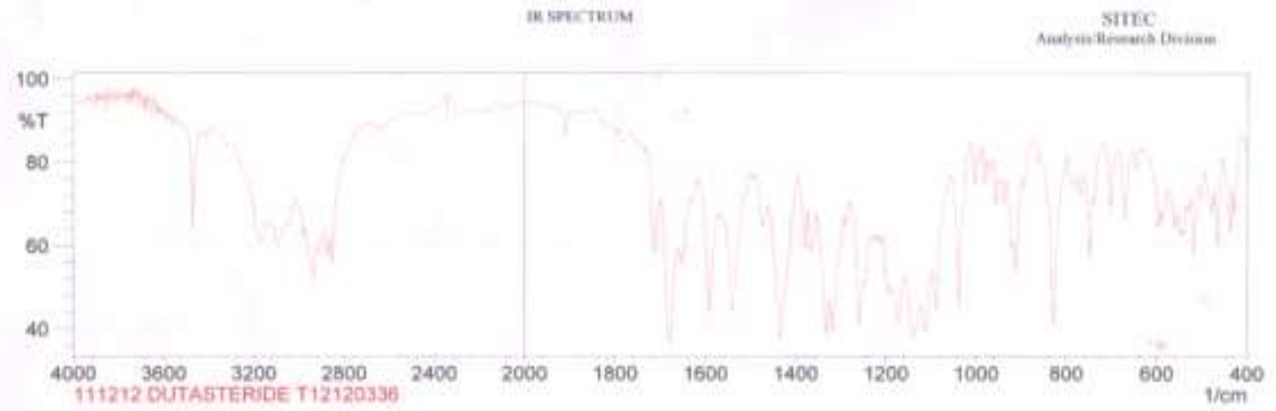

Figure-6

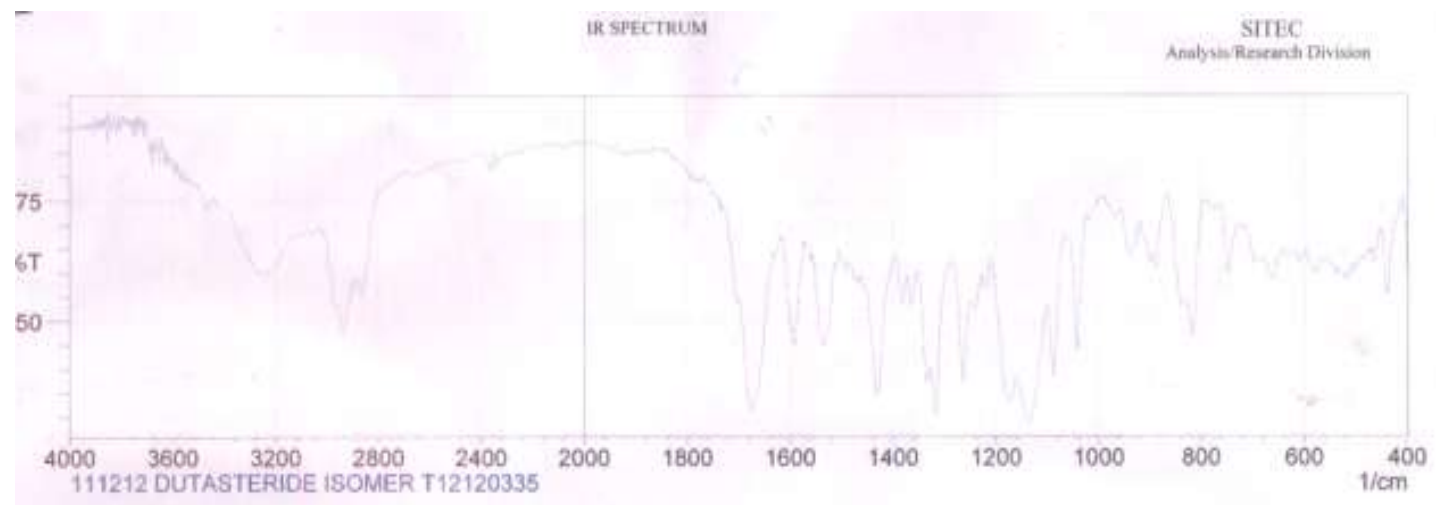

Figure-7

The spectral data of this impurity was compared with that of dutasteride spectral data.

LC-MS analysis exhibited molecular ion for this impurity at $\mathrm{m} / \mathrm{z}=529.4(\mathrm{M}=1)$ and it was same as the mass shown for dutasteride API, hence it was an isomer. The 1H NMR spectrum of dutasteride and $\infty$-dutasteride exhibited a sharp change in $17^{\text {th }}$ position proton and the $13 \mathrm{c}$ NMR of the both showed a sharp shift in the $17^{\text {th }}$ 
position carbon. 1H NMR and the 13c NMR of dutasteride exhibited in Figure-8 and Figure-9, and1H NMR and 13c NMR of isomer impurity exhibited in Figure-10 and Figure-11 respectively.Dutastride and $\infty$-dutasterde $1 \mathrm{H}$ NMR and 13c NMR comparison shown in table-1 and table-2.

Table-1, 1H NMR spectral data of dutasteride and process related impurity.

Dutasteride

\begin{tabular}{|l|l|l|l|l|}
\hline position & Shift/1H/ppm & assignment & Shift/1H/ppm & Assignment \\
\hline 27 & $1 \mathrm{H}-9.35(\mathrm{~s})$ & $\mathrm{NH}$ & $1 \mathrm{H}-9.35(\mathrm{~s})$ & $\mathrm{NH}$ \\
\hline 32 & $1 \mathrm{H}-7.95(\mathrm{~m})$ & Aromatic-H & $1 \mathrm{H}-7.95(\mathrm{~m})$ & Aromatic-H \\
\hline 31 & $1 \mathrm{H}-8.90(\mathrm{~m})$ & & $1 \mathrm{H}-8.90(\mathrm{~m})$ & \\
\hline 29 & $1 \mathrm{H}-8.85(\mathrm{~m})$ & & $1 \mathrm{H}-8.85(\mathrm{~m})$ & \\
\hline 28 & $1 \mathrm{H}-7.35(\mathrm{~m})$ & & $1 \mathrm{H}-7.35(\mathrm{~m})$ & \\
\hline 4 & $1 \mathrm{H}-6.80(\mathrm{~s})$ & Olifenic-H & $1 \mathrm{H}-6.80(\mathrm{~s})$ & Olifenic-H \\
\hline 1 & $1 \mathrm{H}-5.60(\mathrm{~s})$ & Olifenic-H & $1 \mathrm{H}-5.60(\mathrm{~s})$ & Olifenic-H \\
\hline 3 & $1 \mathrm{H}-3.6(\mathrm{~s})$ & $\mathrm{NH}$ & $1 \mathrm{H}-3.6(\mathrm{~s})$ & $\mathrm{NH}$ \\
\hline 20 & $1 \mathrm{H}-3.4(\mathrm{~d})$ & $\mathrm{H}$ & $1 \mathrm{H}-3.4(\mathrm{~d})$ & $\mathrm{H}$ \\
\hline 17 & $1 \mathrm{H}-2.55(\mathrm{~d})$ & $\beta-\mathrm{H}$ & $1 \mathrm{H}-2.7(\mathrm{~d})$ & $\infty-\mathrm{H}$ \\
\hline 7 & $2 \mathrm{H}-2.49(\mathrm{t})$ & $\mathrm{H}$ & $2 \mathrm{H}-2.49(\mathrm{t})$ & $\mathrm{H}$ \\
\hline 16 & $1 \mathrm{H}-2.05(\mathrm{~m})$ & $\mathrm{H}$ & $1 \mathrm{H}-2.05(\mathrm{~m})$ & $\mathrm{H}$ \\
\hline 11 & $2 \mathrm{H}-1.7(\mathrm{~m})$ & $\mathrm{H}$ & $2 \mathrm{H}-1.7(\mathrm{~m})$ & $\mathrm{H}$ \\
\hline $15,12,24,8,21$ & $8 \mathrm{H}-0.9-1.5(\mathrm{~m})$ & $\mathrm{H}$ & $8 \mathrm{H}-0.9-1.5(\mathrm{~m})$ & $\mathrm{H}$ \\
\hline 23 & $3 \mathrm{H}-0.85(\mathrm{~s})$ & Methyl & $3 \mathrm{H}-0.85(\mathrm{~s})$ & Methyl \\
\hline 25 & $3 \mathrm{H}-0.6(\mathrm{~s})$ & Methyl & $3 \mathrm{H}-0.6(\mathrm{~s})$ & Methyl \\
\hline
\end{tabular}

Table-2:13c NMR spectral data of dutasteride and process related impurity.

\begin{tabular}{|l|l|l|}
\hline Position & $13 \mathrm{c}-$ of dutasteride/ppm & $13 \mathrm{c}$ - of Isomer impurity/ppm \\
\hline 18 & 172.38 & 175.03 \\
\hline 2 & 165.126 & 165.20 \\
\hline 4 & 150.43 & 150.51 \\
\hline 28 & 136.99 & $136.58 / 136.59$ \\
\hline 30 & $133.07 / 132.81$ & $132.91 / 132.65$ \\
\hline 35 & $127.96 / 127.91$ & $128.06 / 128.02$ \\
\hline 32 & $127.83 / 127.73$ & $127.09 / 126.86$ \\
\hline 1 & 127.87 & 125.58 \\
\hline 33 & $126.37 / 126.34$ & $123.90 / 124.24$ \\
\hline 34 & $124.21 / 123.90$ & 123.05 \\
\hline 31 & $123.10 / 123.01$ & 122.63 \\
\hline 29 & $122.04 / 121.79$ & $121.72 / 122.06$ \\
\hline 6 & 59.06 & 59.02 \\
\hline 14 & 55.41 & 53.81 \\
\hline 17 & 55.26 & 50.06 \\
\hline 11 & 40.01 & 34.97 \\
\hline 13 & 44.28 & 45.603 \\
\hline 9 & 47.07 & 46.83 \\
\hline 10 & 34.82 & 33.83 \\
\hline 5 & 36.94 & 40.11 \\
\hline 8 & 29.02 & 29.55 \\
\hline 7 & 25.04 & 25.11 \\
\hline 15 & 24.009 & 25.54 \\
\hline 12 & 20.59 & 20.59 \\
\hline 23 & 13.31 & 19.92 \\
\hline 25 & 11.8 & 11.82 \\
\hline & & \\
\hline & & \\
\hline
\end{tabular}




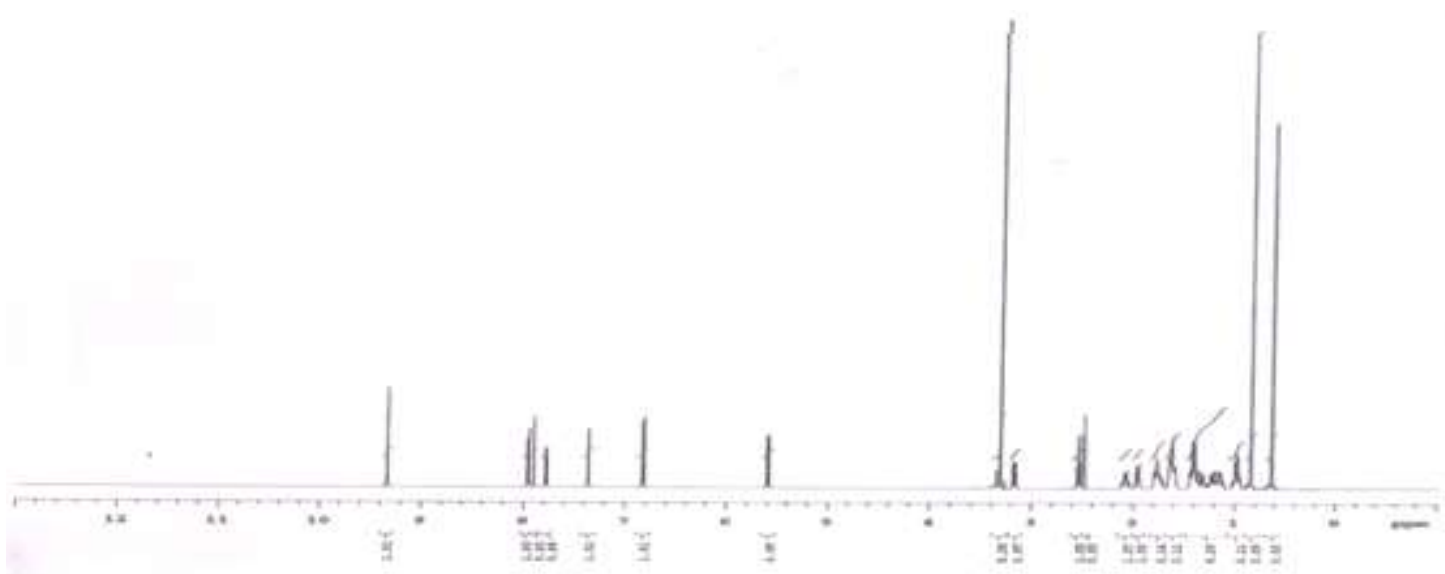

Figure-8

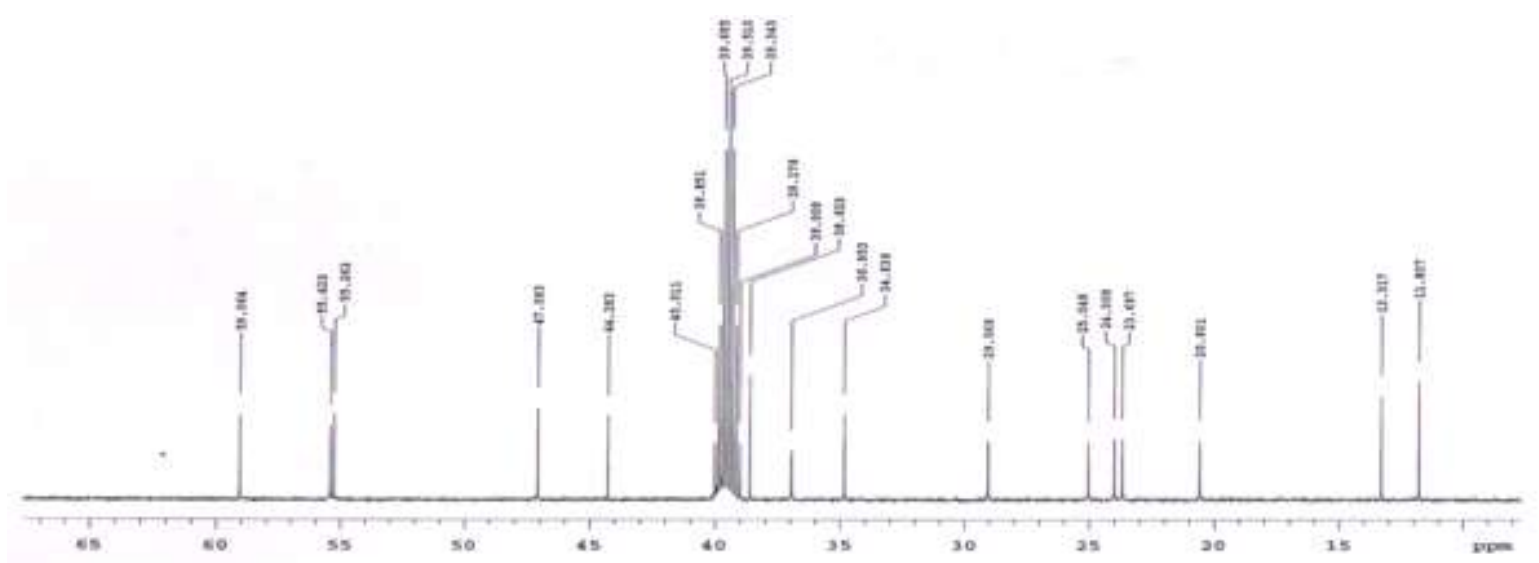

Figure-9

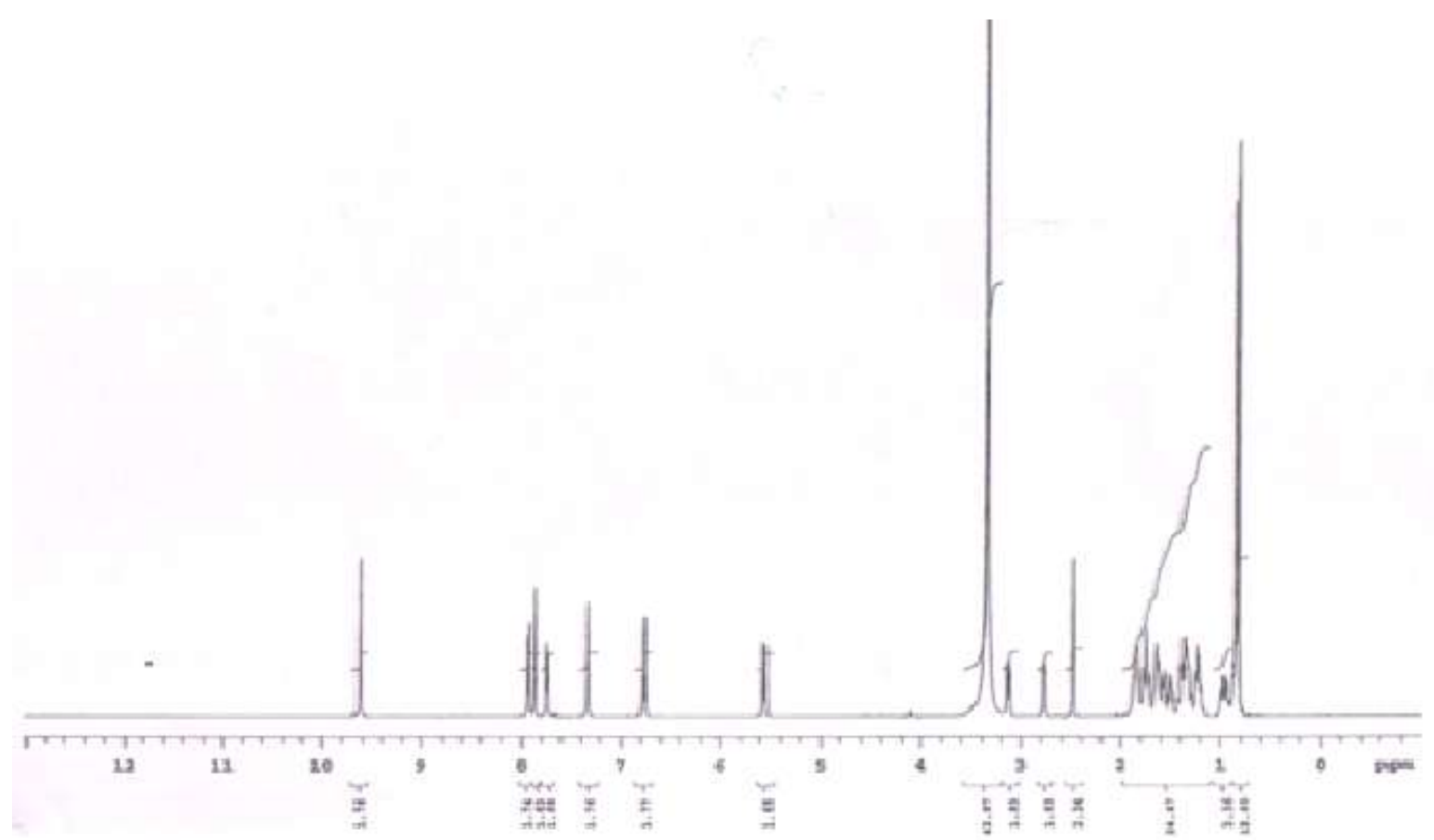

Figure-10 


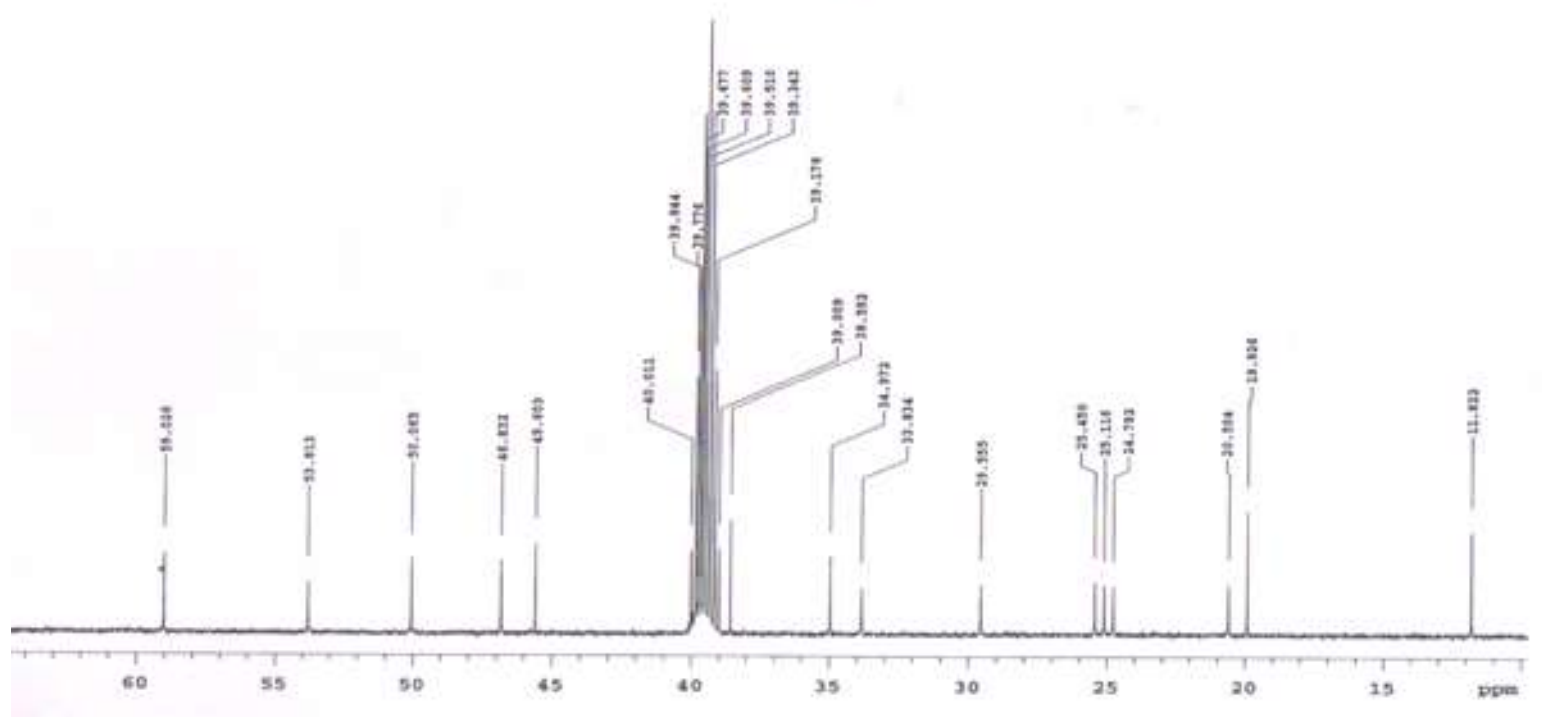

Figure-11

\section{Conclusion}

This research paper describes the synthesis, isolation and structure elucidation of process related isomer impurity of dutasteride. The impurity was separated by normal phase chromatographic technique, by using High performance liquid chromatography (prep-HPLC). The isolated impurity was characterized by using IR, 1H NMR, 13c NMR, and LC-MS spectroscopic technique. The synthesis of impurity was also discussed in brief.

\section{Acknowledgment}

We are very grateful, thanks to Dr Arvind Sawant, Mr, Bhushan Dabolkar for their valuable guidance and Dr Amjad Anwari for analytical support. We are thankful for shophisticated Analytical Instrument facility in Sitec labs Mumbai, India. We wish to thank Cipla Ltd for dutasteride sample.

\section{References}

[1] Hudson, P.B: Boake, R: Trachtenberg, J: Romas, N.A: Rosenblett, S: Naragan, P: Geller, J: Lieber, M.M: Elhilali, M: Norman, R. Urology, 1999, 53(3): 690-692.

[2] Connell, J.D: Bruskewitz, R: Walsh, P: Andriol, G: Lieber, M: Holtgrewe, H.L: Albertsen, P: Roehrborn, C.G: Nickel, J.C: Wang, D,Z: Taylor, A,M: Waldstreicher,J.N: Engl. J. Med, 1998, 338(5): 557-559.

[3] Xie, H.W. Tianjin Pharm, 2002, 14 (3): 15-16.

[4] Harris, G; Azzolina, B; Baginsky, W; Cimis, G; Rasmusson, G.H; Tolman, R. L; Raetz, C. H; Ellsworth, K. Identification and selective inhibition of an isozyme of steroid 5 5 -reductase in human scalp. Proc. Natl. Acad. Sci, U.S.A. 1992, 89, 10787-10791.

[5] Isaacs, J. T. 5 alpha reductase Inhibitors and treatment of benign prostatic hyperplasia. Drugs Today 1993, 29, 335- 342.

[6] Smith, L. S; Tegeler, J. J. Advances in dermatology. Ann. Rep.Med, Chem 1989, 24, 1177- 1186.

[7] Brooks, J. R. Treatment of hirsutism with 5o-reductase inhibitors. Clin, Endocrinol, Metab, 1986, 15, 391- 405.

[8] Gadwood, J. R; Fiedler, V. C. Pathogenesis and treatment of alopecia. Ann. Rep. Med, Chem 1989, 24, 187- 196.

[9] International Conference on Harmonization, Draft Revised. Federal Register Q3B (R) 2000, 65(139), 4479.

[10] K. Satyanarayana, K. Srinivas, V. Himabidu, G. Mahesh Reddy. "Impurity profile study of dutasteride" Pharmazie 2007, 62, 743 746 . 